\title{
Directional solidification of the eutectic LiF-LiYF 4 using Bridgman and micro-pulling down techniques: Microstructural study and some properties
}

\author{
M.F. Acosta ${ }^{1 *}$, S. Ganschow ${ }^{2}$, D. Klimm ${ }^{2}$, S. Serrano-Zabaleta ${ }^{1}$, A. Larrea $^{1}$ \\ and R.I. Merino ${ }^{1}$ \\ ${ }^{1}$ Instituto de Ciencia de Materiales de Aragón (ICMA), CSIC-Universidad de Zaragoza, \\ C/Pedro Cerbuna, 12, 50009, Zaragoza, Spain \\ 2 Leibniz Institute for Crystal Growth (IKZ), Max-Born-Straße 2, 12489, Berlin, Germany
}

\begin{abstract}
The eutectic $\mathrm{LiF}-\mathrm{LiYF}_{4}$ has been solidified by Bridgman and micro-pulling down $(\mathrm{mPD})$ at pulling rates from 4 to $300 \mathrm{~mm} / \mathrm{h}$. The microstructure changes from a coupled, interpenetrated-like one to macrofaceted colonies composed of an approximately triangular arrangement of $\mathrm{LiF}$ fibers inside the $\mathrm{LiYF}_{4}$ matrix as the pulling rate increases. The cross-over pulling rate is around 3 times larger for the mPD method, corresponding to its larger solidification gradient. The crystallographic growth direction of the matrix phase was found using EBSD. Effective medium estimations of the $\mathrm{THz}$ permittivity of the composite predict around the interphase phonon-polariton resonance (wavelength around $17.5 \mu \mathrm{m}$ ) a small permittivity hyperbolic behavior specific of the ordered composite that is tolerant to different relative orientations. Water etching of polished crosssections constitutes a very simple procedure to generate surface micro-holes of predefined size in the $\mathrm{LiYF}_{4}$ matrix.
\end{abstract}

Keywords: Fluoride eutectics, Directional solidification, Micro-hole array, Terahertz, Hyperbolic dispersion relation

\section{Introduction}

Directional solidification of eutectic composites is a self-assembling procedure that allows fabricating from the melt fine homogeneous microstructures controlled by the solidification parameters ${ }^{1}$. As this easily controllable microstructure influences the material properties, the research in directionally solidified ceramic eutectics has seen a revival in the last two decades, mainly

Corresponding author: María F. Acosta. Instituto de Ciencia de Materiales de Aragón. CSIC-Universidad de Zaragoza.

macosta@unizar.es,rmerino@unizar.es

Journal of the European Ceramic Society

Accepted: October 4, 2013 
prompted by the excellent mechanical properties of $\mathrm{Al}_{2} \mathrm{O}_{3}$ based eutectics ${ }^{2}$. Concomitantly, the available procedures to prepare those materials have been recently revised ${ }^{3}$ and new ones further developed ${ }^{4}$. Functional properties of these materials have also been studied ${ }^{5}$, for example luminescence ${ }^{6,7}$, up-conversion ${ }^{8}$, optical wave guiding ${ }^{9}$, red-ox behaviour ${ }^{10}$, ionic conductivity ${ }^{11,12}$, thermoemissive properties ${ }^{13}$, or very recently also as metamaterials and subwavelength guiding structures for the $\mathrm{THz}$ range ${ }^{14,15,16}$. Other interesting applications of microstructured self-assembled eutectics emerge when one considers its use as templates for microstructured slabs/surfaces ${ }^{17,18}$ or sacrificial materials to get rather homogeneous single crystal nanofibers ${ }^{19}$.

A wealth of halide eutectic systems exists, whose equilibrium phase diagrams were studied in the $60 \mathrm{~s}$ and $70 \mathrm{~s}$, and more recently assessed using modern calorimetric equipment and calculation capabilities ${ }^{20}$. This allows us to choose among many systems with the aim of exploiting eutectics.

The present work focuses on $\mathrm{LiF}-\mathrm{LiYF}_{4}$. Both component crystals are good optical materials (transparent and rather stable). $\mathrm{LiYF}_{4}$ (or LYF) is a well known host to many rare-earth ions with efficient laser action ${ }^{21}$. Rare earth ions do not enter the LiF lattice from the melt but are highly soluble in the $\mathrm{LiYF}_{4}$ matrix substituting $\mathrm{Y}$ ions. Consequently selective doping of the eutectic should be easy. Moreover, when control over the microstructure and phase size is possible, optimization of guiding, luminescence or lasing properties could be exerted. In the far IR ( THz) range of the spectrum, the anisotropy of the microstructure can generate anisotropic epsilon near zero or hyperbolic (indefinite) permittivity, useful as metamaterial.

In the past, some growth studies of the eutectic system $\mathrm{LiF}-\mathrm{LiYF}_{4}$ have been done using Bridgman and horizontal directional solidification methods ${ }^{12,22,23}$ up to $20 \mathrm{~mm} / \mathrm{h}$ solidification rate. The micro-pulling down method has been also recently employed to grow and compare $\mathrm{LiF}-\mathrm{LiYF}_{4}$ and $\mathrm{LiF}-\mathrm{LiGdF}_{4}$ eutectics at pulling rates up to $300 \mathrm{~mm} / \mathrm{h}^{24}$ showing a cross-over pulling rate from coupled to cellular microstructure. These works were performed separately and different microstructures were observed. In this work, we cover the pulling rate range from 4 to $300 \mathrm{~mm} / \mathrm{h}$ and compare the microstructure of this eutectic obtained by both directional solidification methods. The growth procedure has influence in sample size, kind of microstructure (coupled or colonies) and microstructure size, all features that may be relevant to applications. One first exploration of its crystallography by EBSD on unseeded grown crystals has been done, as well as the estimation, using an effective medium approach, of its permittivity in the $\mathrm{THz}$ range. Finally, we report on the preparation of microperforated $\mathrm{LiYF}_{4}$ substrates by water surface etching of the disperse LiF phase.

\section{Experimental procedure}

Eutectic $\mathrm{LiF}-\mathrm{LiYF}_{4}$ boules of $14 \mathrm{~mm}$ diameter and around $50 \mathrm{~mm}$ length (see Fig. 1) have been grown through the directional solidification Bridgman method in a three zone furnace with an approximate thermal gradient of up to $40 \mathrm{~K} / \mathrm{cm}$. The starting powder composition was $79.6 \mathrm{~mol} \% \mathrm{LiF}-20.4 \mathrm{~mol}_{\%} \mathrm{YF}_{3}$ 


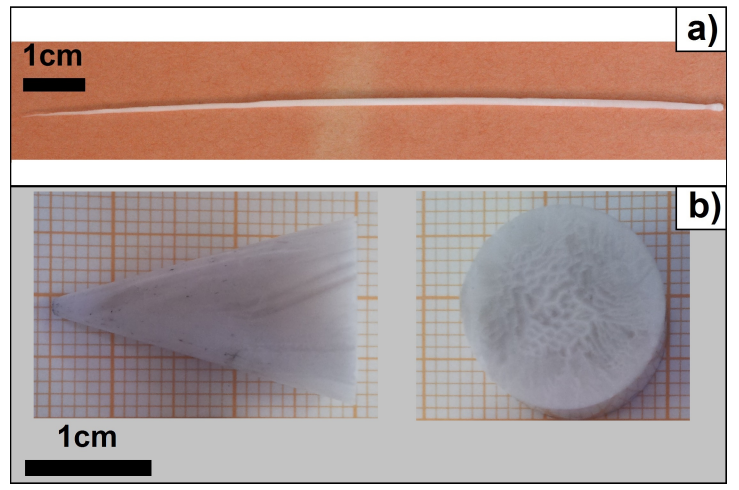

Figure 1: Photograph of a mPD grown rod (a); and of a Bridgman grown ingot (cone region and transverse cut thick slice (b).

(pure eutectic), or $79.6 \mathrm{~mol} \% \mathrm{LiF}-20.2 \mathrm{~mol} \% \mathrm{YF}_{3}-0.2 \mathrm{~mol} \% \mathrm{ErF}_{3}$ (Er-doped eutectic). Powders of $99.99 \%$ purity (Alfa Aesar) were used and previously dried at $400^{\circ} \mathrm{C}$. The mechanically mixed powder was introduced -typically $14 \mathrm{~g}$ charge- in a graphite carbon crucible and was melted at the eutectic temperature of $702^{\circ} \mathrm{C}^{20}$. As traces of oxygen or moisture certainly affects the growth of rare earth fluorides and its optical properties, extreme dry and oxygen free conditions are desirable ${ }^{25}$. A vacuum of $10^{-2}$ mbar was reached in the chamber. In order to eliminate the oxygen contamination an $\operatorname{Ar}(99.95 \%$ purity) atmosphere with a fluorinating agent $-\mathrm{NH}_{4} \mathrm{~F} \cdot \mathrm{HF}$ - was used in the experiments. Pulling rates from 4 to $60 \mathrm{~mm} / \mathrm{h}$ were used. Pure $\mathrm{LiF}-\mathrm{LiYF}_{4}$ eutectic samples were grown between 4 and $10 \mathrm{~mm} / \mathrm{h}$. Samples doped with $1 \mathrm{~mol} \%$ of $\mathrm{ErF}_{3}$ for later optical measurements were prepared between 10 and $60 \mathrm{~mm} / \mathrm{h}$. As Er would enter into the scheelite $\mathrm{LiYF}_{4}$ phase, $\mathrm{LiF}-\mathrm{LiY}{ }_{0.99} \mathrm{Er}_{0.01} \mathrm{~F}_{4}$ eutectic samples would be obtained from the doped mixtures.

For higher pulling rates, the micro-pulling down ( $\mathrm{mPD}$ ) method was used to grow eutectic rods of $\mathrm{LiF}-\mathrm{LiYF}_{4}$ typically around $1 \mathrm{~mm}$ in diameter (see Fig. 1). A higher gradient of approximately $100 \mathrm{~K} / \mathrm{cm}^{26}$ in the equipment permits higher rates on cost of smaller sample sizes because of the increased thermal stresses ${ }^{27}$. The $\mathrm{mPD}$ setup allowed a vacuum of $10^{-5}$ mbar in a 35 liter vacuum-tight steel chamber, avoiding moisture. LiF (Alfa Aesar, 99.99\%) and $\mathrm{YF}_{3}$ powders were mixed covering the range between $79.8 \mathrm{~mol} \% \mathrm{LiF}-20.2 \mathrm{~mol}_{\%} \mathrm{YF}_{3}$ and $81.7 \mathrm{~mol} \% \mathrm{LiF}-18.3 \mathrm{~mol} \% \mathrm{YF}_{3} . \mathrm{YF}_{3}$ was synthesized in this case from the oxide $\left(\mathrm{Y}_{2} \mathrm{O}_{3}\right.$, AlfaAesar, $\left.99.99 \%\right)$ by a hydrofluorination method ${ }^{28}$ under reactive atmosphere of HF and Ar. The absence of oxygen in the starting compounds was controlled by DTA measurements ${ }^{24}$. A platinum wire seed and an $\mathrm{Ar}$ atmosphere (1 bar, $99.999 \%$ purity, $<1$ ppm water) were used to grow samples at pulling rates from 15 to $300 \mathrm{~mm} / \mathrm{h}$.

Both series, Bridgman and mPD together, covers the range for the $\mathrm{LiF}-\mathrm{LiYF}_{4}$ eutectic system from 4 to $300 \mathrm{~mm} / \mathrm{h}$. Transverse and longitudinal cross-sections of the samples were polished (usually dry polished or using oil based diamond 
paste) and observed in a Merlin Field Emission Scanning Electron Microscope SEM from Carl Zeiss (Germany). Phase interspacing and volumetric fraction of the phases were obtained from SEM images by using the software Digital Micrograph from Gatan Inc. The crystallographic orientation and growth directions of the samples were determined from electron backscatter diffraction (EBSD) experiments carried out using a Nordlys model detector form HKL Technology (Denmark) integrated in the aforementioned Carl Zeiss electron microscope. The experiments were performed with the sample tilted $70^{\circ}$ using $20 \mathrm{keV}$ electrons and $1.3 \mathrm{nA}$ of probe current intensity. Chemical analysis of the samples were performed using a scanning electron microscope (model 6400, JEOL, Tokyo, Japan) equipped with an X-ray detector INCA 300 X-Sight from Oxford Instruments for energy dispersive X-ray analysis (EDS). The ZAF method was used to obtain the elemental composition ${ }^{29}$. EDS spectra were recorded for $600 \mathrm{~s}$ at $20 \mathrm{kV}$. Standards of $\mathrm{SrF}_{2}, \mathrm{Y}$ and $\mathrm{CaSiO}_{3}$ were used for F, Y and O quantification, respectively. Li cannot be detected with EDS.

\section{Results and discussion}

\subsection{Microstructure}

\subsubsection{Solidification of $\mathrm{LiF}-\mathrm{LiYF}_{4}$ by the Bridgman method}

SEM images of several samples of $\mathrm{LiF}-\mathrm{LiYF}_{4}$ polished transverse crosssections grown by Bridgman method are in Fig. 2. At $4 \mathrm{~mm} / \mathrm{h}$ (Fig. 2a) the microstructure shown is a coupled, interpenetrated one with irregular shaped LiF cross-sections. At some places eutectic cells with quasi-lamellar of rod-tolamellar arrangement inside surrounded by coarser interpenetrated areas, are seen. This is the dominant microstructure of the samples pulled at $10 \mathrm{~mm} / \mathrm{h}$ (Fig. 2b). The microstructure changes into macrofaceted eutectic colonies when increasing the pulling rate above $40 \mathrm{~mm} / \mathrm{h}$ (Fig. 2c, 2d and 3). Areas with regular triangular fiber ordering of at least $300 \mu \mathrm{m} \times 200 \mu \mathrm{m}$ were found inside the macrofaceted colonies (Fig. 2c and d).

Bright precipitates embedded in the matrix where observed in all samples (see Fig2e). This phase has a size comparable to the constituent majority phases. EDS microanalysis indicate that it contains $\mathrm{Y}, \mathrm{O}$ and $\mathrm{F}$ with around 22 to 25 atomic \% oxygen. It seems reasonable to assume that the precipitates are yttrium oxyfluoride ${ }^{30}$. The $\mathrm{REF}_{3}-\mathrm{RE}_{2} \mathrm{O}_{3}$ systems $(\mathrm{RE}=$ rare earth element or yttrium, respectively) contain three forms of oxyfluorides, where the tetragonal $\mathrm{RE}_{4} \mathrm{O}_{3} \mathrm{~F}_{6}$ exhibits some degree of nonstoichiometry ${ }^{31}$, a reasonable candidate for the observed precipitates.

Finally, some dendrites of LiF where observed at the outer rim of the ingots in samples grown with pulling rates larger than $10 \mathrm{~mm} / \mathrm{h}$, concomitant with the formation of eutectic cells. The doping with Erbium (substitution of $1 \mathrm{~mol} \%$ of $\mathrm{Y}^{3+}$ by $\mathrm{Er}^{3+}$ ) of some samples growth at 10,40 or $60 \mathrm{~mm} / \mathrm{h}$ pulling rate samples is not expected to influence the microstructure. First, no segregation of erbium would be expected in Erbium doped $\mathrm{LiYF}_{4}$ single crystals because the distribution coefficient of $\mathrm{Er}^{3+}$ in $\mathrm{LiYF}_{4}$ is very close to 1 , based on previous 


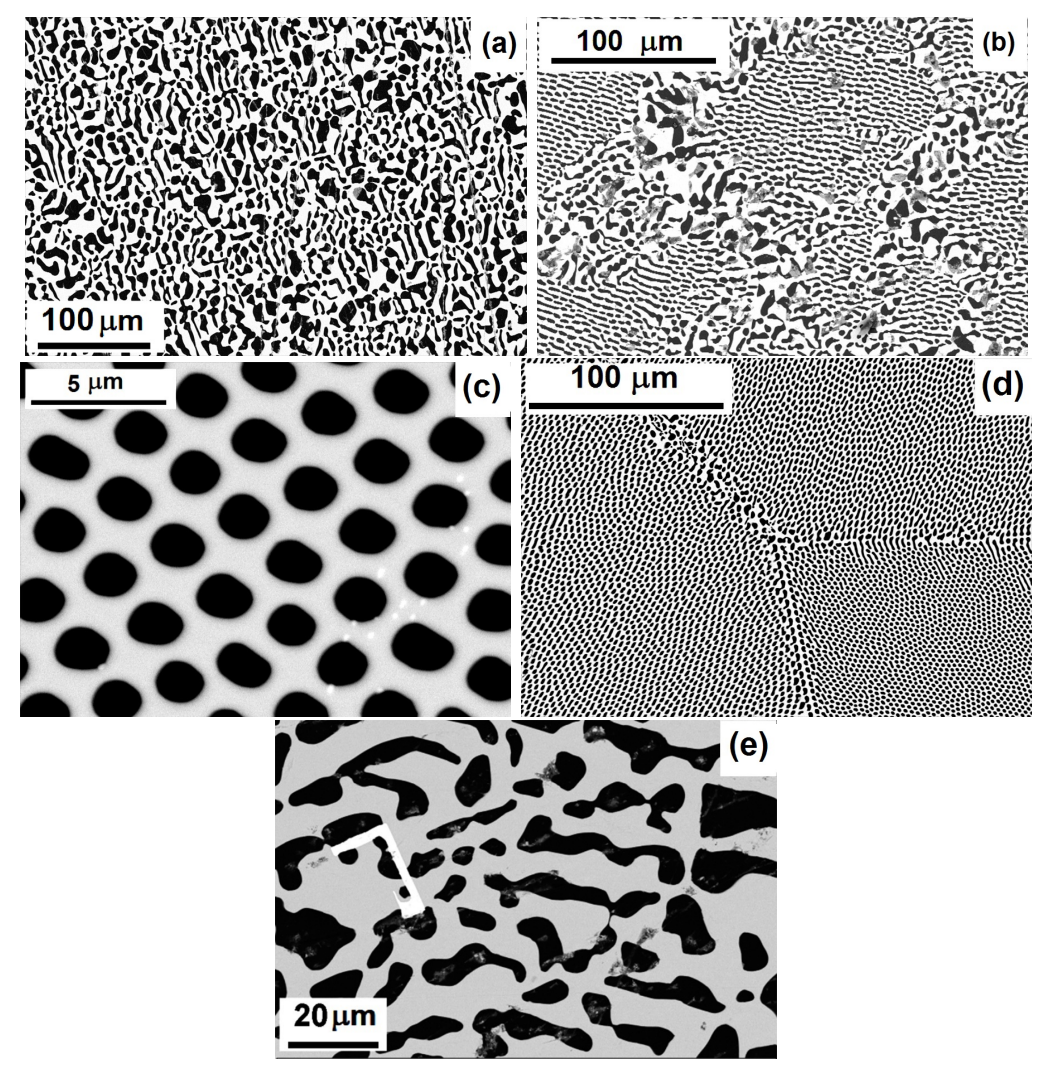

Figure 2: SEM micrographs of transverse cross-sections $\mathrm{LiF}-\mathrm{LiYF}_{4}$ grown by Bridgman method. Dark phases correspond to LiF. Samples grown at $4 \mathrm{~mm} / \mathrm{h} \mathrm{(a)}$ and (e); $10 \mathrm{~mm} / \mathrm{h} \mathrm{(b);} 40 \mathrm{~mm} / \mathrm{h} \mathrm{(c)} \mathrm{and} 60 \mathrm{~mm} / \mathrm{h}(\mathrm{d})$. The bright faceted phase in Fig. 2e contains oxygen.

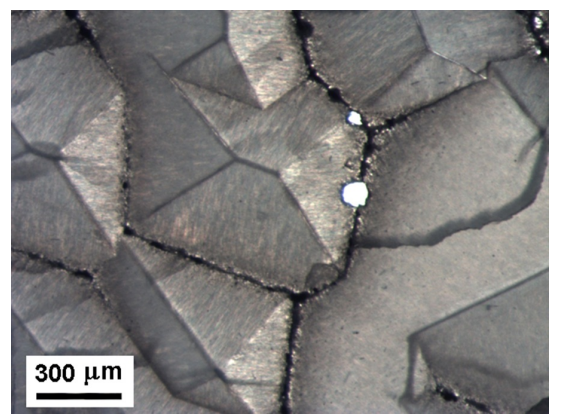

Figure 3: Optical transmission image of a $\mathrm{LiF}-\mathrm{LiYF}_{4}$ sample grown at $60 \mathrm{~mm} / \mathrm{h}$ by the Bridgman method. The macrofaceted colonies are clearly seen. 
works ${ }^{32,33,34}$. Secondly, although Thoma reports very different LiF content in $\mathrm{LiF}-\mathrm{LiYF}_{4}$ and $\mathrm{LiF}-\mathrm{LiErF}_{4}$ eutectics ${ }^{35}$, all latter publications (Ivanova ${ }^{36}$, Harris $^{37}$, Fedorov ${ }^{38}$ ) give almost the same composition for the LiF- $\mathrm{LiREF}_{4}$ $(\mathrm{RE}=\mathrm{Y}, \mathrm{Er})$ of approximately $20 \mathrm{~mol} \% \mathrm{LiF}$ and $80 \mathrm{~mol} \% \mathrm{REF}_{3}$.

\subsubsection{Solidification of $\mathrm{LiF}-\mathrm{LiYF}_{4}$ by the micro-pulling down (mPD) method}

The microstructure of samples prepared by $\mathrm{mPD}$ at pulling rates from 15 to $300 \mathrm{~mm} / \mathrm{h}$ was described by Klimm et $\mathrm{al}^{24}$. In Fig. 4 we give SEM micrographs for completeness. The microstructure of the samples grown between 15 and $60 \mathrm{~mm} / \mathrm{h}$ was found to be fully interpenetrated as in Fig. 4a. From 120 to $300 \mathrm{~mm} / \mathrm{h}$ the change to macrofaceted eutectic colonies was observed (Fig. 4b).

We scanned the initial composition from 79.8 to $81.7 \mathrm{~mol} \% \mathrm{LiF}$ and found an upper limit in order to get samples free of LiF primary dendrites. This limit was established at approximately $81 \mathrm{~mol} \% \mathrm{LiF}$. For a higher LiF content, dendrites of $\mathrm{LiF}$ start to appear in the transverse cross-section SEM images (Fig. 4b inset).

Moreover, much fewer and smaller oxygen containing precipitates were observed in the samples grown by $\mathrm{mPD}$ than by Bridgman. EDS area microanalysis were done on polished cross-sections at different positions all over the samples. Areas to acquire the individual spectra were $400 \times 400 \mu \mathrm{m}^{2}$ size (Bridgman samples) and $60 \times 40 \mu \mathrm{m}^{2}$ or $80 \times 60 \mu \mathrm{m}^{2}$ (mPD samples), and give an estimate of the total oxygen content of the samples, whether dissolved in $\mathrm{LiYF}_{4}$ or in segregated phases. We measure an average oxygen content for the samples (area analysis) of $0.4 \pm 0.1 \mathrm{wt} \%$ in Bridgman grown samples and almost zero $(0.15 \pm 0.12 \mathrm{wt} \%$ oxygen, near to the limit of sensibility) in mPD grown samples. The better vacuum in the $\mathrm{mPD}$ setup is the reason for that.
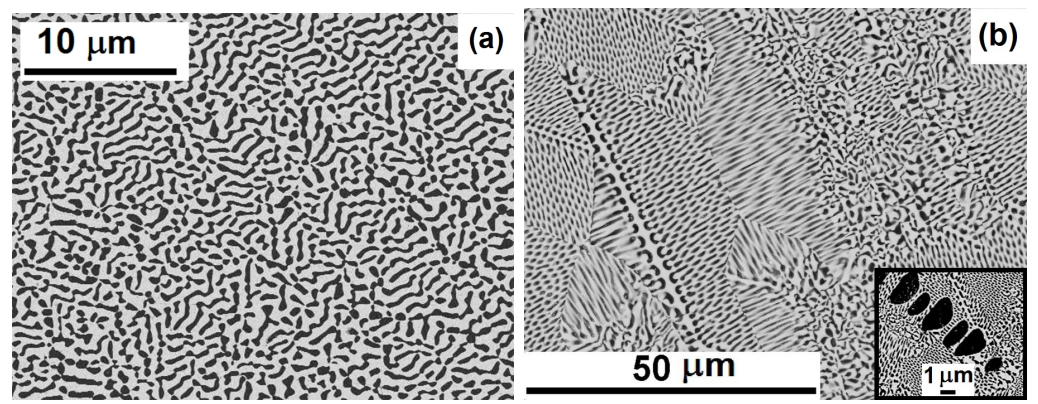

Figure 4: SEM images of three transverse cross-sections of $\mathrm{LiF}-\mathrm{LiYF}_{4}$ samples grown at $15 \mathrm{~mm} / \mathrm{h}$ (a) and $300 \mathrm{~mm} / \mathrm{h}$ (b) by the $\mathrm{mPD}$ method. Dark phases correspond to $\mathrm{LiF}$. Inset in (b) shows a detail of a $\mathrm{LiF}$ dendrite due to an excess of $2 \mathrm{~mol} \% \mathrm{LiF}$ in the starting composition.

\subsubsection{Coupled growth}

The crossover pulling rate for the non-coupled macrofaceted microstructure occurs at different pulling rates in Bridgman (between 10 and $40 \mathrm{~mm} / \mathrm{h}$ ) and 
micro-pulling down (between 120 and $300 \mathrm{~mm} / \mathrm{h}$ ). This is explained by the limiting condition for a coupled growth ${ }^{39}$ Eq.(1):

$$
\frac{m \cdot \Delta C}{D} \ll \frac{G}{v}
$$

Where $m$ is the slope of the liquidus line in the phase diagram; $\Delta C$ is the deviation from the eutectic composition; $D$ is the diffusion coefficient; $G$ the thermal gradient and $v$ is the pulling rate. Only the gradient $G$ changes by changing the procedure, and the micro-pulling down method has typically a larger gradient (see the experimental Section 2). Consequently at a pulling rate of $60 \mathrm{~mm} / \mathrm{h}$, we find uncoupled growth for the Bridgman samples and a coupled microstructure (growth) for the micro-pulling down ones.

\subsubsection{Longitudinal cross-sections}

The overall alignment of the microstructure can be better observed in longitudinal cross-sections. Fig. 5 shows the microstructure of samples solidified at $4 \mathrm{~mm} / \mathrm{h}$ (Fig. 5a, Bridgman) and $300 \mathrm{~mm} / \mathrm{h}$ (Fig. 5b, mPD). It can be seen that at low pulling rates the phases are elongated along the pulling direction. At high pulling rates, the LiF phase grows perpendicular to the plane of faceting of the solid-liquid interface, which is not strictly parallel to the pulling direction (see Fig. 3).

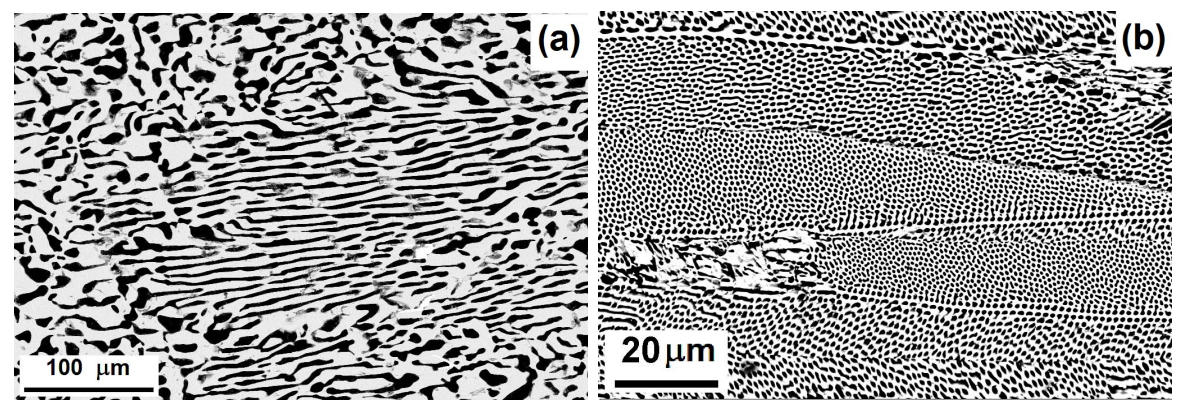

Figure 5: (a) SEM image of a longitudinal cross-section of a $4 \mathrm{~mm} / \mathrm{h}$ sample of $\mathrm{LiF}-\mathrm{LiYF}_{4}$ by Bridgman. (b) SEM image of a longitudinal cross-section of a $300 \mathrm{~mm} / \mathrm{h}$ sample of $\mathrm{LiF}-\mathrm{LiYF}_{4}$ by $\mathrm{mPD}$. The growth directions lie parallel to the horizontal axis of the page.

\subsubsection{Interspacing measurements}

Phase interspacing was estimated from SEM images of transverse crosssection. Intespacing values from 10.5 to 1.5 microns were obtained (Fig. 6). Both series of samples can be fitted to the same relationship $\left(a^{2} v=K\right.$, where $v$ is the pulling rate and $a$ is the interspacing), with $K=(122.8 \pm 0.1) \mu \mathrm{m}^{3} / \mathrm{s}$. The volumetric fractions measured by image analysis, $f$ (the filling fraction), were in both cases $40 \pm 1 \mathrm{vol} \% \mathrm{LiF}$, in good agreement with the $40 \%$ theoretical value. The LiF fiber diameter $\phi$ can be scaled down to $1 \mu \mathrm{m}$ by increasing the pulling rate to the maximum accessible value of $300 \mathrm{~mm} / \mathrm{h}(\phi=1.05 a \sqrt{f})$. 


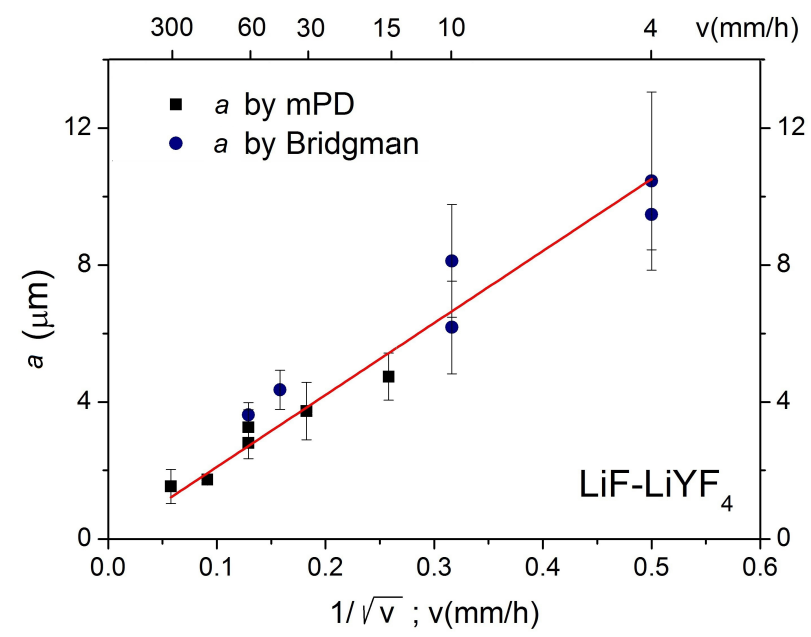

Figure 6: Interspacing as a function of the square root of the pulling rate for the eutectic system $\mathrm{LiF}-\mathrm{LiYF}_{4}$ by Bridgman (circles) and mPD (squares) methods.

\subsubsection{Crystal growth direction}

The crystallographic growth directions were determined by EBSD experiments performed on transverse polished cross-sections of samples processed by Bridgman at $4 \mathrm{~mm} / \mathrm{h}$ and by $\mathrm{mPD}$ at 15,120 and $300 \mathrm{~mm} / \mathrm{h}$. Only diffraction patterns corresponding to the $\mathrm{LiYF}_{4}$ phase were collected as the LiF phase got selectively etched upon the final step of the chemical polishing with colloidal silica, applied in order to reduce mechanical polishing damage over the specimen to a minimum. Patterns displaying identical crystal orientation were acquired at different points on each sample, as the one presented in Fig. 7, showing that the matrix grows in each case as a single crystal with small mosaicity. The growth directions were, however, different for each sample. Only in the sample solidified at the fastest pulling rate, $300 \mathrm{~mm} / \mathrm{h}$ by $\mathrm{mPD}$, it was observed that the growth direction was near the c axis of the $\mathrm{LiYF}_{4}$ crystal lattice. The [001] crystallographic direction formed an angle of $9.8 \pm 3.2$ degrees with respect to the rod axis, which is considered to be the growth direction. This value was averaged out of 11 patterns acquired from locations spread all over the cross-section of the sample.

\subsection{THz permittivity of the eutectic composite}

Well aligned directionally solidified eutectics have been proposed and are being studied as polaritonic metamaterials in the $\mathrm{THz}^{16}$. In particular, hyperbolic permittivity is predicted in some regions of the $\mathrm{THz}$ range, allowing devising self-focusing, and subwavelength guiding or filter-polarizer applications. The hyperbolic indefinite permittivity arises because of the different sign of the real part of the permittivity of matrix and aligned disperse phase (ideally rods) at 

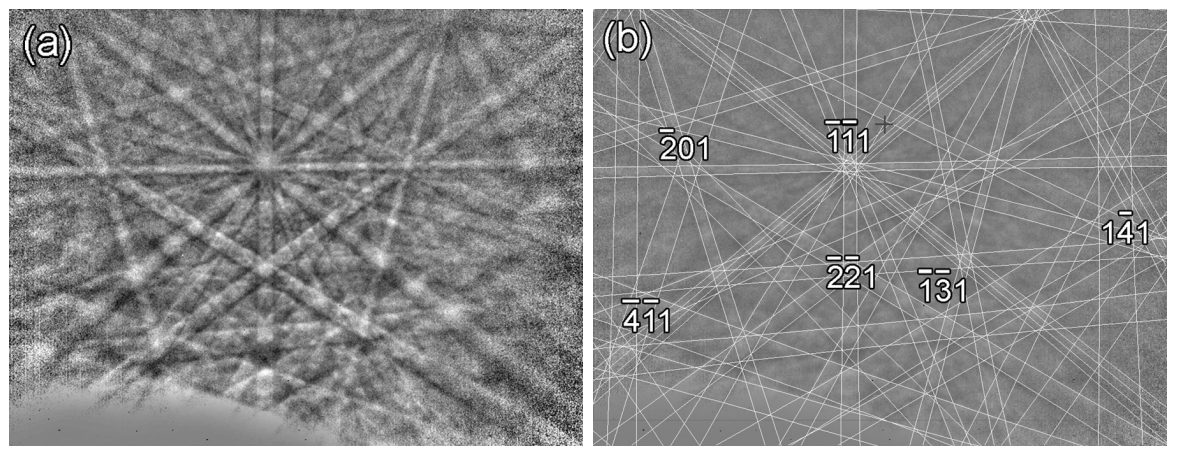

Figure 7: EBSD pattern acquired from the matrix of the $300 \mathrm{~mm} / \mathrm{h}$ by $\mathrm{mPD}$ sample. (a) As registered. (b) After indexing of the diffraction bands to determine the crystal orientation.

specific wavelengths. This occurs also in the present composites. Although difficulties arise because of the fact that the matrix is itself anisotropic (uniaxial, and consequently, optically birefringent), and so, the specific crystallographic orientation with respect to the overall direction of alignment, needs to be known beforehand. Moreover, the degree of alignment in the composite we are studying here is far from perfect, as can be seen in Fig. 5. The good news is that there exist very well ordered regions with fibrous alignment inside large macrofaceted colonies that would allow small elements to be designed and constructed. In the present section we have attempted to evaluate roughly how sensitive the $\mathrm{THz}$ response of the composite is towards changes in the crystallographic growth direction of the matrix with respect to the alignment direction of the $\mathrm{LiF}$ rods. For that, we have used an effective medium approach.

\subsubsection{Calculation of the permittivity}

Effective medium approaches are valid only in the long wavelength limit compared to the interspacing of the scattering units. For hyperbolic photonic crystal structures, S. Foteinopoulou et $\mathrm{al}^{40}$ have shown that if $\omega(a / 2 \pi c)$ is smaller than 0.1 , the principal values of the effective dielectric tensor can be calculated with the Maxwell-Garnett expressions for 2D two phase composites when the Electric field is perpendicular to the rod axis (perpendicular polarization) or with a volume fraction weighted addition for the parallel polarization ( $E$ parallel to the rod axis). $\omega$ is the angular frequency of the electromagnetic wave, $a$ is the period of the composite microstructure in the transverse direction and $c$ is the speed of light. According to Fig. 6, the faster pulled samples would fulfil this criterion for wavelengths longer than $15 \mu \mathrm{m}$. To calculate the permittivity of a $\mathrm{LiF}-\mathrm{LiYF}_{4}$ eutectic material, let us describe its microstructure as $\mathrm{LiF}$ aligned fibers embedded in a $\mathrm{LiYF}_{4}$ matrix with a $40 \%$ volumetric fraction of $\mathrm{LiF}$.

We compute the dielectric response of the system when the propagation is in the plane of periodicity (perpendicular to the LiF rod axis), for both perpendicular and parallel polarization. As the matrix $\mathrm{LiYF}_{4}$ is a birefringent 
crystal with a scheelite tetragonal structure ${ }^{41}$, we need to specify the orientation between the LiF fibers, the c axis in the tetragonal structure of the matrix and the electric field of the electromagnetic wave ${ }^{42}$. We will only calculate the cases for either c parallel (Fig. 8a) or perpendicular (Fig. 8b) to the LiF fibers axes.
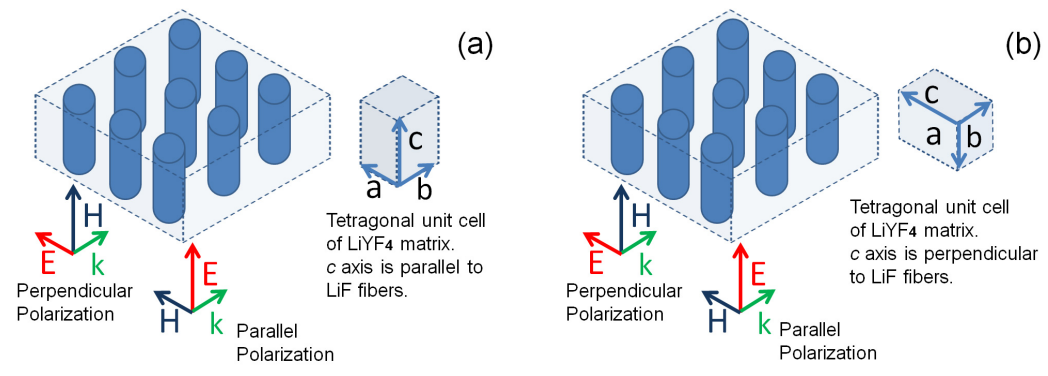

Figure 8: Sketch of the model for the eutectic metamaterial system used in the effective medium approach. The $\mathrm{LiF}$ particles are embedded in a $\mathrm{LiYF}_{4}$ birefringent matrix. (a) The $\mathrm{c}$ axis is parallel to the LiF fibers. With this configuration the $\mathrm{c}$ axis is perpendicular (for the named perpendicular polarization) or parallel (parallel polarization) to the electric field $E$. (b) The c axis is perpendicular to the LiF fibers. Note that with this configuration the $\mathrm{c}$ axis is parallel (for the named perpendicular polarization) or perpendicular (parallel polarization) to the electric field $E$. The third unequivalent principal direction (within this model) in case (b), $E$ perpendicular to the $\mathrm{LiF}$ fibers and to the $\mathrm{c}$ axis, results in the same permittivity that case (a), with perpendicular polarization. $E, H$ and $k$ are the electric field, magnetic field and propagation direction, respectively. $\mathrm{a}, \mathrm{b}$ and $\mathrm{c}$ represent the three axes of the tetragonal unit cell of the $\mathrm{LiYF}_{4}$ matrix.

The Maxwell Garnett formula ${ }^{43}$ for the effective dielectric response function in two dimensions is given by Eq.(2):

$$
\varepsilon_{\text {eff }}^{\perp}(\omega)=\varepsilon_{\text {matrix }}(\omega) \frac{(1+f) \varepsilon_{\text {fibers }}(\omega)+(1-f) \varepsilon_{\text {matrix }}(\omega)}{(1-f) \varepsilon_{\text {fibers }}(\omega)+(1+f) \varepsilon_{\text {matrix }}(\omega)}
$$

where $f$ is the volume filling fraction of the fibers, and $\varepsilon_{\text {matrix }}$ and $\varepsilon_{\text {fibers }}$ are the permittivities of matrix and fibers, respectively. This applies when the electric field is perpendicular to the fibers axes. When $\mathrm{E}$ is parallel to the fibers axes, the appropriate formula for the effective dielectric function is the average dielectric function ${ }^{44}$, given by Eq.(3):

$$
\varepsilon_{\text {eff }}^{\|}(\omega)=(f) \varepsilon_{\text {fibers }}(\omega)+(1-f) \varepsilon_{\text {matrix }}(\omega)
$$

We calculated the permittivity using the data tabulated by Palik ${ }^{45}$ for $\mathrm{LiF}$. For the matrix $\mathrm{LiYF}_{4}$, we reproduced the spectra simulated by Salaün et al ${ }^{42}$.

\subsubsection{Results of the calculation}

The calculated permittivity values are given in Fig. 9b and c. In Fig. 9a the permittivity of the matrix is given for comparison. It shows some ranges 
with hyperbolic dispersion (opposite $\operatorname{sign}$ of $\varepsilon_{\text {eff }}^{\| \prime}$ and $\varepsilon_{e f f}^{\perp}$ ). Most of these regions are already present in the matrix behavior, around $150 \mathrm{~cm}^{-1}$ or $260 \mathrm{~cm}^{-1}$ for example, with small energy shifts and changes in the magnitude of the permittivity contrast.

The region around the localized surface modes (around $560 \mathrm{~cm}^{-1}$ or $18 \mu \mathrm{m}$ ) is the one where features specific of the composite are present. Absolute values of real and imaginary part of the permittivity are here the smallest, and so, the absorption somehow limited. When the electric field is perpendicular to the $\mathrm{LiF}-\mathrm{LiYF}_{4}$ interface, surface phonon-polariton modes are excited whose energy depends on the shape and size of the dispersed phase. Peaks in transmittance spectra should be found for configurations with $E$ perpendicular to the LiF fibers. Its position will shift between $17.5 \mu \mathrm{m}\left(560 \mathrm{~cm}^{-1}\right)$ and $18 \mu \mathrm{m}$ $\left(555 \mathrm{~cm}^{-1}\right)$ when the crystallographic orientation of the matrix changes, as seen in the extreme cases shown in the figures. We have attempted to measure the transmittance spectrum in this region of a large slice, around 95 microns thick, of Bridgman grown $\mathrm{LiF}-\mathrm{LiYF}_{4}$. But the transmittance is still too small and no measurable transmission has been detected at wavelengths longer than $15.4 \mu \mathrm{m}$ (below $650 \mathrm{~cm}^{-1}$ ). Probably, thinner and more homogeneous samples are required to have useful transmittance values and test the appropriateness of this simple description.

As small interparticle distances are required for the model to apply, at pulling rates around $15 \mathrm{~mm} / \mathrm{h}$ the application wavelength stays at around $50 \mu \mathrm{m}$ $\left(200 \mathrm{~cm}^{-1}\right)$, where there is no evident advantage in building a composite eutectic compared to the performance of the single phase birefringent matrix. Around $560 \mathrm{~cm}^{-1}(18 \mu \mathrm{m}), 300 \mathrm{~mm} / \mathrm{h}$ pulling rates are required, so that the size of the $\mathrm{LiF}$ rods do not add extra shifts to the indefinite $\varepsilon$ region. Note that, although other simpler fibrous eutectic systems do exist ${ }^{16,39}$, better behaving as metamaterials in the $\mathrm{THz}$, in this case we have $40 \mathrm{vol} \%$ of LiF fiber, a large, convenient fiber filling fraction, not usually found among well-ordered eutectics.

\subsection{Selective etching of the minority LiF phase: microporous $\mathrm{LiYF}_{4}$ surfaces}

The samples turned to be sensitive to the wet vehicle during the polishing procedure. LiF is slightly soluble in water ${ }^{46}$, while $\mathrm{LiYF}_{4}$ is insoluble ${ }^{47}$. This can be a convenient tool to generate etched microstructured $\mathrm{LiYF}_{4}$ surfaces. Bulky as well as transverse cut thin slices of samples grown at $60 \mathrm{~mm} / \mathrm{h}$ and $4 \mathrm{~mm} / \mathrm{h}$ (finer and larger microstructural features) were polished with the use of water or ethanol as solvent and subsequently immersed in water -ethanol or soapwater mixtures. Optical microscopy observations were made after each step for both samples. It was found that $\mathrm{LiF}$ particles become sensibly corroded by long time immersion in water plus ethanol mixtures. Ultrasonication generated deeper degradation of the $\mathrm{LiF}$ particles and the corroded material dropped off the surface of the LiF grains. In the case of large particles (dendrites), which could be observed under optical microscopy, complete elimination of the LiF took place. The $\mathrm{LiYF}_{4}$ polished surface did not show traces of water corrosion under such treatments. Fig. 10 shows a SEM micrograph of an etched surface. 

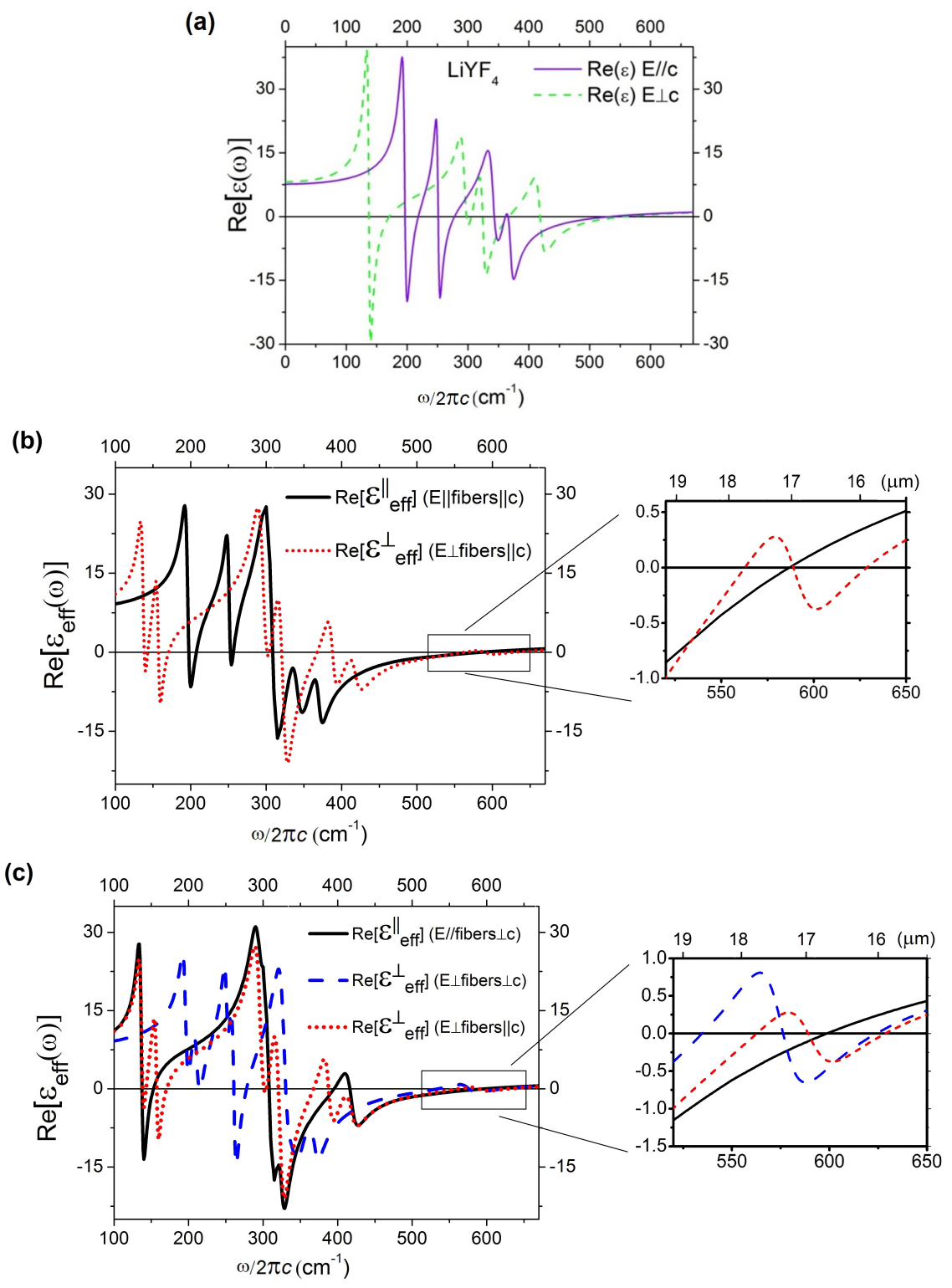

Figure 9: Real part of the permittivity for the $\mathrm{LiYF}_{4}$ matrix (a) and the effective medium when the fibers axes are parallel (b) and perpendicular (c) to c axis of the matrix unit-cell. In (c) we also replot for its comparison the real part of the permittivity for the case of fibers axes parallel to c axis, when $E$ is perpendicular to both of them (red short dotted line). On the right side of (b) and (c) an inset with finer details of the calculations between 520 and $650 \mathrm{~cm}^{-1}$ are presented. 
The etch depth of small particles could not be measured by microscopy observations, although it is for sure at least comparable to the width of the $\mathrm{LiF}$ particles at the polished surface. Relatively long times are required and we did not get to dissolve completely all the LiF present in the samples, nor even if they were grown at a small pulling rate and had larger pores for the solvent to enter into the channels. Consequently this is a very simple procedure to generate surface micro-holes of predefined size (the size of the eutectic microstructure), which, to a big extent will be stable under many chemical conditions and solvents (even in water containing solvents).

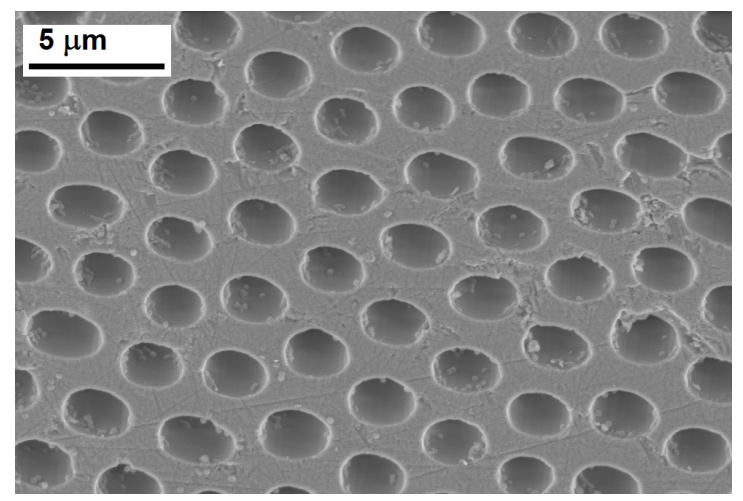

Figure 10: SEM micrograph of a soap-water etched surface of $\mathrm{LiF}^{-\mathrm{LiYF}_{4}}$ eutectic.

\section{Conclusions}

Using directional solidification (Bridgman and $\mathrm{mPD}$ methods), we have fabricated a polaritonic eutectic system made of LiF elongated particles dispersed in $\mathrm{LiYF}_{4}$ birefringent matrix. The microstructure size and shape varies with the pulling rate range from 4 to $300 \mathrm{~mm} / \mathrm{h}$ and follows the same proportionality ratio $a^{2} \propto 1 / v$, as required by the Hunt-Jackson rule. The microstructure changes from a coupled, interpenetrated-like one at low pulling rates to macrofaceted colonies composed of an approximately triangular arrangement of parallel LiF fibers inside the $\mathrm{LiYF}_{4}$ matrix. The cross-over pulling rate from the coupled to the macrofaceted-colony microstructure is around 3 times larger (between 120 and $300 \mathrm{~mm} / \mathrm{h}$ ) for the $\mathrm{mPD}$ method, corresponding to its larger solidification gradient. Diffraction (EBSD) patterns display identical crystal orientation all over the sample cross-section. As a hyperbolic material in the $\mathrm{THz}$ range, one does not expect advantage of the composite eutectic material over the birefringent $\mathrm{LiYF}_{4}$ matrix at wavelengths larger than 25 microns. Around the interphase phonon-polariton resonance excited with perpendicular polarization $(\sim 18 \mu \mathrm{m})$, a small permittivity hyperbolic behavior specific of the ordered composite is expected, that is tolerant to different rod axis to matrix crystalline orientations. Water etching of polished cross-sections eliminates LiF up to a 
limited depth very slowly, and then, it is easily controllable. This is a very simple procedure to generate surface micro-holes of predefined size in the $\mathrm{LiYF}_{4}$ matrix.

\section{Acknowledgments}

Authors would like to acknowledge the financial support by EU under the project NMP4-SL-2008-213669-ENSEMBLE. MFA acknowledges Ministerio de Educación, Cultura y Deporte (Spain) for the FPU scholarship.

\section{References}

1. Orera VM, Peña JI, Larrea Á, Merino RI, Oliete PB. Engineered selforganized microstructures using directional solidification of eutectics. $\mathrm{Ce}$ ram. Trans. 2001;225:185-196.

2. LLorca J, Orera VM. Directionally solidified eutectic ceramic oxides. Prog. Mater. Sci. 2006;51(6):711-809.

3. Orera VM, Peña JI. Directional solidification. In: Bansal N, Boccaccini A, editors. Ceramic and Composites Processing Methods. The American Ceramic Society, John Wiley \& Sons Inc.; 1 ed.; 2012, p. 4187-4457.

4. Gurauskis J, Lennikov V, de la Fuente GF, Merino RI. Laser-assisted, crack-free surface melting of large eutectic ceramic bodies. J. Eur. Ceram. Soc. 2011;31(7):1251-1256.

5. Merino RI, Peña JI, Larrea Á, de la Fuente GF, Orera VM. Melt grown composite ceramics obtained by directional solidification: structural and functional applications. Recent Res. Dev. Mater. Sci. 2003;4:1-24.

6. Merino RI, Pardo JA, Pena JI, Orera VM. Microstructure-size dependence of the $1.520 \mu \mathrm{m} \mathrm{Er}{ }^{3+}$ luminescence lifetime in $\mathrm{Al}_{2} \mathrm{O}_{3}-\mathrm{ZrO}_{2}$ eutectic melt growth composites. Appl. Phys. Lett. 2002;80(4):589-591.

7. Merino RI, Pardo JA, Pena JI, De La Fuente GF, Larrea Á, Orera VM. Luminescence properties of $\mathrm{ZrO}_{2}-\mathrm{CaO}$ eutectic crystals with ordered lamellar microstructure activated with $\mathrm{Er}^{3+}$ ions. Phys. Rev. B. 1997;56(17):10907.

8. Balda R, García-Revilla S, Fernández J, Merino RI, Peña JI, Orera VM. Near infrared to visible upconversion of $\mathrm{Er}^{3+}$ in $\mathrm{CaZrO}_{3} \mathrm{CaSZ}$ eutectic crystals with ordered lamellar microstructure. J. Lumin. 2009;129(12):14221427 .

9. Orera VM, Peña JI, Merino RI, Lázaro JA, Vallés JA, Rebolledo MA. Prospects of new planar optical waveguides based on eutectic microcomposites of insulating crystals: $\mathrm{The}_{\mathrm{ZrO}}(\mathrm{c})-\mathrm{CaZrO}_{3}$ erbium doped system. Appl. Phys. Lett. 1997;71(19):2746-2748. 
10. Laguna-Bercero MA, Larrea Á, Peña JI, Merino RI, Orera VM. Structured porous Ni-and Co-YSZ cermets fabricated from directionally solidified eutectic composites. J. Eur. Ceram. Soc. 2005;25(8):1455-1462.

11. Merino RI, de Francisco I, Peña JI. Ionic conductivity in directionally solidified $\mathrm{Al}_{2} \mathrm{O}_{3}-\mathrm{ZrO}_{2}\left(3 \%\right.$ molY $\left.\mathrm{O}_{3}\right)$ near eutectic composites. Solid State Ionics. 2007;178(3):239-247.

12. Trnovcová V, Labaš V, Fedorov PP, Meleshina VA, Sobolev BP, Bárta C. Microstructure and physical properties of superionic eutectic composites of the $\mathrm{LiF}-\mathrm{RF}_{3}(\mathrm{R}=$ rare earth element) system. Solid State Ionics. 1999; 119(1):173-180.

13. Nakagawa N, Ohtsubo H, Waku Y, Yugami H. Thermal emission properties of $\mathrm{Al}_{2} \mathrm{O}_{3} / \mathrm{Er}_{3} \mathrm{Al}_{5} \mathrm{O}_{12}$ eutectic ceramics. J. Eur. Ceram. Soc. 2005; 25(8):1285-1291.

14. Pawlak DA, Turczynski S, Gajc M, Kolodziejak K, Diduszko R, Rozniatowski $\mathrm{K}$, et al. How far are we from making metamaterials by selforganization? the microstructure of highly anisotropic particles with an SRR-like geometry. Adv. Funct. Mater. 2010;20(7):1116-1124.

15. Myroshnychenko V, Stefanski A, Manjavacas A, Kafesaki M, Merino RI, Orera VM, et al. Interacting plasmon and phonon polaritons in aligned nano-and microwires. Opt. Express. 2012;20(10):10879-10887.

16. Reyes-Coronado A, Acosta MF, Merino RI, Orera VM, Genanakis G, Katsarakis N, et al. Self-organization approach for $\mathrm{THz}$ polaritonic metamaterials. Opt. Express. 2012;20(13):14663-14682.

17. Larrea Á, Orera VM. Porous crystal structures obtained from directionally solidified eutectic precursors. J. Cryst. Growth. 2007;300(2):387-393.

18. Pawlak DA, Kolodziejak K, Turczynski S, Kisielewski J, Rozniatowski K, Diduszko R, et al. Self-organized, rodlike, micrometer-scale microstructure of $\mathrm{Tb}_{3} \mathrm{Sc}_{2} \mathrm{Al}_{3} \mathrm{O}_{12}-\mathrm{TbScO}_{3}: \mathrm{Pr}$ eutectic. Chem. Mater. 2006;18(9):24502457 .

19. Soler R, Molina-Aldareguia JM, Segurado J, Llorca J, Merino RI, Orera VM. Micropillar compression of LiF [111] single crystals: Effect of size, ion irradiation and misorientation. Int. J. Plast. 2012;36:50-63.

20. Dos Santos IA, Klimm D, Baldochi SL, Ranieri IM. Thermodynamic modeling of the $\mathrm{LiF}_{-} \mathrm{YF}_{3}$ phase diagram. J. Cryst. Growth. 2011;360(0):172-175.

21. Gomes L, Librantz AFH, Jagosich FH, Alves WAL, Ranieri IM, Baldochi SL. Energy transfer rates and population inversion of $4 \mathrm{I} 11 / 2$ excited state of $\mathrm{Er}^{3+}$ investigated by means of numerical solutions of the rate equations system in Er: $\mathrm{LiYF}_{4}$ crystal. J. Appl. Phys. 2009;106(10):103508-103508. 
22. Trnovcová V, Starostin MY, Čička R, Fedorov PP, Bárta Č, Labaš V, et al. Microstructure and fast ionic conduction of inorganic fluoride and oxide eutectic composites prepared from the melt. Solid State Ionics. 2000; 136:11-17.

23. Barta Č, Fendrych F, Recker K, Tříska A, Wallrafen F. On the influence of the crystallization conditions on the microstructure of the directionally solidified eutectic of the $\mathrm{LiF}-\mathrm{LiYF}_{4}$ system. Cryst. Res. Technol. 1991; 26(4):413-424.

24. Klimm D, Acosta MF, dos Santos IA, Ranieri IM, Ganschow S, Merino RI. Growth of self organized eutectic fibers from LiF-rare earth fluoride systems. In: MRS Proceedings; vol. 1508. Cambridge Univ Press; 2013, p. mrsf12-1508. doi:/10.1557/opl.2013.487.

25. Maier D, Bertram R, Klimm D, Fornari R. Influence of the atmosphere on the growth of $\mathrm{LiYF}_{4}$ single crystal fibers by the micro-pulling-down method. Cryst. Res. Technol. 2009;44(2):137-140.

26. Maier D, Rhede D, Bertram R, Klimm D, Fornari R. Dopant segregations in oxide single-crystal fibers grown by the micro-pulling-down method. Opt. Mater. 2007;30(1):11-14.

27. Orera VM, Larrea Á. NaCl-assisted growth of micrometer-wide long single crystalline fluoride fibres. Opt. Mater. 2005;27(11):1726-1729.

28. Guggenheim H. Growth of highly perfect fluoride single crystals for optical masers. J. Appl. Phys. 1963;34(8):2482-2485.

29. Castaing R, Descamps J. Sur les bases physiques de l'analyse ponctuelle par spectrographie-X. J. Phys. Radium. 1955;16(4):304-317.

30. Sobolev BP, Fedorov PP, Shteynberg DB, Sinitsyn BV, Shakhkalamian GS. On the problem of polymorphism and fusion of lanthanide trifluorides. I. The influence of oxygen on phase transition temperatures. J. Solid State Chem. 1976;17(1):191-199.

31. Niihara K, Yajima S. Studies of rare earth oxyfluorides in the hightemperature region. Bull. Chem. Soc. Jpn. 1972;45(1):20-23.

32. Abell JS, Harris IR, Cockayne B, Plant JG. A DTA study of zone-refined $\operatorname{LiRF}_{4}(\mathrm{R}=\mathrm{Y}, \mathrm{Er})$. J. Mater. Sci. 1976;11(10):1807-1816.

33. Ranieri I, Baldochi S, Santo A, Gomes L, Courrol L, Tarelho L, et al. Growth of $\mathrm{LiYF}_{4}$ crystals doped with holmium, erbium and thulium. $J$. Cryst. Growth. 1996;166(1):423-428.

34. Silva FR. Crescimento de fibras de $\mathrm{LiYF}_{4}$ dopadas com $\mathrm{Nd}^{3+}$ e $\mathrm{Er}^{3+}$ para aplicações em lasers de estado sólido. Master's thesis; Universidade de São Paulo; 2008. 
35. Thoma RE. Rare-earth halides. Prog. Sci. Technol. Rare Earths. 1966; 2:90-92.

36. Ivanova IA, Petrova M, Podkolzina I. The $\mathrm{ErF}_{3}-\mathrm{LiF}$ system. Russ. J. Inorg. Chem. (English Translations). 1975;20(8):1273-1274.

37. Harris IR, Safi H, Smith NA, Altunbas M, Cockayne B, Plant JG. The relationship between crystal growth behaviour and constitution in the systems $\mathrm{LiF}-\mathrm{LuF}_{3} \mathrm{LiF}-\mathrm{ErF}_{3}$ and $\mathrm{LiF}-\mathrm{YF}_{3}$. J. Mater. Sci. 1983;18:1235-1243.

38. Fedorov PP. Systems of alkali and rare-earth metal fluorides. Russ. J. Inorg. Chem. 1999;44:1703-1727.

39. Orera VM, Peña JI, Oliete PB, Merino RI, Larrea Á. Growth of eutectic ceramic structures by directional solidification methods. J. Cryst. Growth. 2012;360(0):99-104.

40. Foteinopoulou S, Kafesaki M, Economou EN, Soukoulis CM. Twodimensional polaritonic photonic crystals as terahertz uniaxial metamaterials. Phys. Rev. B. 2011;84(3):035128.

41. Sen A, Chaplot SL, Mittal R. Effects of pressure and temperature on the vibronic as well as the thermodynamic properties of $\mathrm{LiYF}_{4}$ and $\mathrm{LiYbF}_{4} . J$. Physics: Condens. Matter. 2002;14(5):975.

42. Salaün S, Fornoni MT, Bulou A, Rousseau M, Simon P, Gesland JY. Lattice dynamics of fluoride scheelites: I. Raman and infrared study of $\mathrm{LiYF}_{4}$ and $\mathrm{LiLnF}_{4}(\mathrm{Ln}=\mathrm{Ho}$; Er; Tm and $\mathrm{Yb})$. J. Physics: Condens. Matter. 1997;9(32):6941-6956.

43. Sihvola A. Metamaterials handbook. Theory and phenomena of metamaterials. 2009.

44. Kirchner A, Busch K, Soukoulis CM. Transport properties of random arrays of dielectric cylinders. Phys. Rev. B. 1998;57:277-288.

45. Palik ED. Handbook of optical constants of solids; vol. 3. Boston: Academic Press; 1998.

46. Stubblefield CB, Bach RO. Solubility of lithium fluoride in water. J. Chem. Eng. Data. 1972;17(4):491-492.

47. Weber MJ. Handbook of optical materials. CRC Press; 2002. 